\title{
Adsorption of Cr (VI) From Polluted Water using Activated Carbon Prepared from Vincarosea Apocynaceae
}

\author{
O.Sreedevi, K.Ravindhranath
}

\begin{abstract}
The performance removal of chromium (VI) from polluted water is discussed in this paper. The sorption characteristic of Nitric Acid activated carbon derived from Vincarosea Apocynaceae plants through oxidation process and was proposed for the removal of $\mathrm{Cr}$ (VI) from polluted solutions. The surface chemistry characteristics of the prepared adsorbent were analysis by XRD, FTIR and SEM-EDAX. The effects are determined for removal of chromium they are initial concentration, $P H$ level and adsorbent dose. The metal ion removal was $\mathrm{pH}$ dependent and, to a lesser extent, ionic strength. Kinetics data were found to follow the pseudo-second order kinetic model. Activation thermodynamic parameters, such as activation enthalpy $\left(\Delta H^{*}\right)$, activation entropy $\left(\Delta S^{*}\right)$, activation Gibbs free energy $\left(\Delta G^{*}\right)$ and activation energy $(E)$, have been evaluated and the possible adsorption mechanism also was suggested.
\end{abstract}

Key Words: Vincarosea Apocynaceae Activated Carbon, Chromium (VI), Adsorption Isotherms and Kinetics.

\section{INTRODUCTION}

Nowadays, heavy metals are among the most important pollutants in source and treated water and becoming a severe public health problem. The main problem in this entire world is heavy toxic metals are obtained while water is contaminated [1]. In the environment, the species of metallic run off and mining activities [2]. Coming to aquatic water, it consists of four oxidation states they are di, tri, penta and hexa states. These states are combined to the trivalent chromium and hexavalent state. Trivalent chromium acts as the micro nutrients which is essential for glycolsis whereas hexavalent chromium is 500 times more toxic than the trivalent chromium. Thus, the presence of $\mathrm{Cr}$ (VI) ions in the environment is posing serious problems and causing great public concern [3]. These tissues will irritate the plan and animal's skin because of the oxidant agent is strong. This agent easily passes to the skin from the environments of aquatic [4]. According to USEPA, the permissible level of $\mathrm{Cr}$ (VI) in drinking water should be less than $100 \mu \mathrm{g} / \mathrm{L}$ [5].

Many physical-chemical methods, included reduction [6], ion exchange [7], precipitation [8] and membrane separation [9], have been proposed for $\mathrm{Cr}(\mathrm{VI})$ removal from industrial effluent. However, these methods are often inefficient and/or cost disadvantageous when they are used to remove heavy metal ions from solution [10]. Adsorption methods

Revised Manuscript Received on September 05, 2019.

O.Sreedevi, Research scholar, Department of chemistry, ANU, Guntur District, A.P, India

K.Ravindhranath, Professor, Department of Chemistry, Koneru Lakshmaiah Education Foundation, Guntur District, A.P, India are increased because of the domestic effluents, agriculture

were found to be more effective and attractive due to its lower costs and the higher efficiency of heavy metal ions removal from waste water [11].

To obtain good adsorbent in the water, mainly active carbons are used and consist of mainly adsorptive sites. To remove the chromium ions from polluted water, active carbons are used and active carbons plays important role in the adsorption process. There will be huge number of waste products and expensive natural materials to perform the operations. There will be no expensive regeneration for this disposed one. Hence the capacity of contaminant sorption is very high and available at low cost [13]. Here various types of studies are given, they are seaweeds [17], Eucalyptus Bark [15], Peanut Husks Carbon [19], Beech Sawdust [14] Bagasse Fly Ash, Coir Pitch [18], Green Algae [16], Activated Slag, Zeolite Tuff [20], Fabric Cloth, etc. All these studies need some high sate adsorbents. Here the operational cost is reduced by $36 \%$, capital cost is reduced by $20 \%$ and at last the total cost is reduced by $28 \%$.

Some adsorbents are required which are very effective in an economical way. Basically, to remove chromium (VI) an adsorbent is used, the adsorbent is named as Vincarosea Apocynaceae. This adsorbent is indicated in the literature survey. Vincarosea Apocynaceae belongs to the family of Vincarosea Apocynaceae which consists of Apocynaceae carbons. Hence from waste water the chromium is removed based on this Vincarosea Apocynaceae adsorbent. To estimate the behavior of adsorption in chromium (VI), thermodynamic functions are used. This is obtained at different temperatures. Here we investigate the parameters like temperature, $\mathrm{pH}$ concentration and agitation time. Classical methods are introduced by using new techniques The new techniques are given as FT-IR, SEM, and EDX \& XRD. By using NVAC, the chromium (VI) is removed from the polluted water.

\section{MATERIALS AND METHODS}

\subsection{Chemicals And Reagents}

By using the double stilled water, the investigation for chemicals and reagents is done. Based on the grade of A.R the entire investigation process is performed. Hence from this solutions are prepared.

\subsection{Materials Of Adsorbent}

In India, the evergreen shrub is growled by using the Cape periwinkle. sadabahar or Rosea periwinkle is the

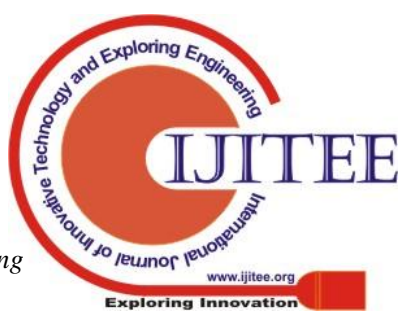


domestic name of the Cape periwinkle. Vincarosea is the botanical name of Vinca Rosea and available from the family of Apocynaceae. Plantae kingdom and Magnoliophyta are the kingdom and division for the Vinca Rosea.

Basically, it is called as the flowering plant. This plant consists of ducotyledons and gentianales, which is mainly used for the purpose of medicinal.

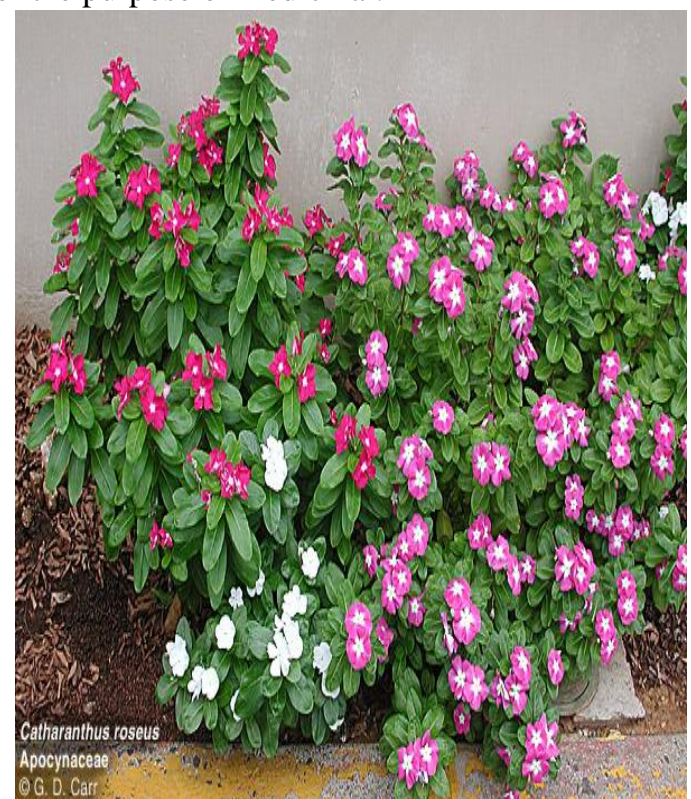

Fig. 1: Home / Herbs Information / Vinca Rosea Information-Uses And Benefits

Basically, white layer form flower or Vincarosea is known as the Vincarosea. This is a type of flower, which is equal to the ever green shrub and charmed and grow in the south western and Eastern Madagascar. Here, it is a native plant. Ornamental property is introduced by the European colonist to recognize the invasion. In the tropical and sub tropical regions it is mainly grown.

The flower which is named as Vincarosea consists of oblong and oval in shape. This provides the covering of glossy and waxed. By using a pale midrib and short petiole, there will be arranged in the pairs. It mainly consists of five petals which are equal to loves.

The flower Vinca rosea will be grown in the regions of well drained soil and infertile regions. This flower will be dried in the cases of heavy fertile in the soil. Branching and full growth process is used for the purpose of pinching occasionally. After the process of blooming, the flower will not died. This flower is mainly used to treat the disease of Leukemia which is mainly occurred in the children. The leaf growth is reduced if the Phytoplasmas infection is occurred. It mainly consists of 70 different types of alkaloid which are mainly used for the types of indole. The alkaloids used in this are given as serpentine, reserpine vinblastine and ajamalicine.

\subsection{Preparation Of Adsorbent}

Activated carbons were prepared from Vincarosea Apocyanacea plant stem material. The earthy matter is removed from the raw material using double distilled water. After removing, this will cut in small pieces and dried. The activated material was ground and sieved in to desired particle sizes. By using concentrated nitric acid, activated carbons are prepared. The weight of acid volume is given as 1:1 for $24 \mathrm{hrs}$. In double stilled water, the materials that charred are washed.

\subsection{Adsorbate}

By dissolving the potassium dichromate, the adsorbent obtains a stock solution. This process is done only in double distilled water. Different types of experiments are performed using the double distilled water.

\subsection{Adsorbent Characterization}

By using standard testing methods, parameters were analyzed. Due to adsorption and area is high; the activated carbons are most widely used. The activity of adsorption is determined by the chemical nature and pore structure. From table 1, the characteristics of physics and chemical are given.

Table 1: Physico-chemical Properties. SAMPLE NAME: NVAC

\begin{tabular}{|c|c|c|}
\hline S.NO & $\begin{array}{c}\text { CHARACTER } \\
\text { (UNITS) }\end{array}$ & RESULTS \\
\hline 1 & $\begin{array}{c}\text { Bulk Density in } \\
\mathrm{gm} / \mathrm{cc}\end{array}$ & 0.333 \\
\hline 2 & $\begin{array}{c}\text { Moisture } \\
\text { Content in \% }\end{array}$ & 6.503 \\
\hline 3 & $\begin{array}{c}\text { Loss on } \\
\text { Ignition in } \%\end{array}$ & 81.873 \\
\hline 4 & $\begin{array}{c}\text { Ash Content in } \\
\%\end{array}$ & 6.553 \\
\hline 5 & $\begin{array}{c}\text { Particle Size in } \\
\mu \mathrm{m}\end{array}$ & 75 \\
\hline 6 & $\mathrm{pH}$ & 7.133 \\
\hline 7 & $\begin{array}{c}\text { Point of zero } \\
\text { charge }\end{array}$ & 7.22 \\
\hline 8 & $\begin{array}{l}\text { Water soluble } \\
\text { Matter in } \%\end{array}$ & 3.627 \\
\hline 9 & $\begin{array}{l}\text { Acid soluble } \\
\text { Matter in } \%\end{array}$ & 41.54 \\
\hline 10 & $\begin{array}{c}\text { Iodine Number } \\
\mathrm{mg} / \mathrm{gms}\end{array}$ & 487.667 \\
\hline 11 & $\begin{array}{c}\text { Decolorizing } \\
\text { Power in } \\
\mathrm{mg} / \mathrm{gms}\end{array}$ & 295.333 \\
\hline 12 & $\begin{array}{c}\text { Surface } \\
\text { Functional } \\
\text { Groupr in \% } \\
\end{array}$ & \\
\hline a) & Carboxyl & 0.274 \\
\hline b) & Lactone & 0.025 \\
\hline c) & Phenol & 0.013 \\
\hline 13 & $\begin{array}{c}\text { Total Basic } \\
\text { Groups }\end{array}$ & 0.716 \\
\hline
\end{tabular}




\subsection{Analysis Of FTIR}

By using Fourier Transform Infrared Spectroscopy (FTIR), the examination of NVAC is done. Active carbons are mixed in the sample disc with $1 \mathrm{mg}$ and 500mg of NVAC of NVAC. By using all this the mortar is agate in vacuum by pressing the mixture which is resulted for $5 \mathrm{~min}$ as 6tones $/ \mathrm{cm}^{2}$ and again after $5 \mathrm{~min}$ as 10 tones $/ \mathrm{cm}^{2}$. By using HATR Spectrum the $400-4000 \mathrm{~cm}^{-1}$ value is measured having USA ID No: SN/LE-735/00735.

2.7 Scanning Electron Microscopy-Energy Dispersive XRay Spectroscopy (SEM-EDX)

By using the double-sided adhesive carbon tape, the NVAC is stubbed. Basically, NVAC is named the surface of powered carbonaceous material. It is coated using the platinum coater which obtained from the model of SEMSu1510 Hitachi. SEMSu1510 Hitachi model mainly consists a set of samples in the micro photographs. By using the accelerating voltage, the EDX is analyzed at $5 \mathrm{kv}$. The resolution of this is maintained at $3 \mathrm{~nm}$ and compared to the actual size, it is 3,00,000 times greater.

Table 2: EDX - Elemental Analysis(Before) SAMPLE NAME: NVAC 1

\begin{tabular}{|c|c|c|c|c|c|}
\hline Composition & CK & NK & OK & Crk & Total \\
\hline Energy (eV) & 0.3 & 0.5 & 0.7 & 5.2 & \\
\hline $\begin{array}{c}\text { Wt \% } \\
\text { (Mass } \\
\text { ratios) }\end{array}$ & 72.3 & 11.2 & 16.5 & ---- & 100 \\
\hline $\begin{array}{c}\text { At \% } \\
\text { (Atomic } \\
\text { percentages) }\end{array}$ & 71.1 & 13.0 & 15.9 & ---- & 100 \\
\hline
\end{tabular}

Table 3: EDX - Elemental Analysis(After) SAMPLE NAME: NVAC 2

\begin{tabular}{|c|c|c|c|c|c|}
\hline Composition & CK & NK & OK & Crk & Total \\
\hline Energy (eV) & 0.3 & 0.5 & 0.7 & 5.2 & \\
\hline $\begin{array}{c}\text { Wt \% } \\
\text { (mass ratios) }\end{array}$ & 63.5 & 9.3 & 12.1 & 15.1 & 100 \\
\hline $\begin{array}{c}\text { At \% } \\
\text { (atomic } \\
\text { percentages) }\end{array}$ & 61.4 & 10.6 & 12.3 & 15.7 & 100 \\
\hline
\end{tabular}

\subsection{X-ray Diffraction (XRD) Analysis}

By using the $X$ Celebrator $X$ ', samples for the analysis of $\mathrm{XRD}$ is prepared. For the purpose of radiation, (0.150$54 \mathrm{~nm}$ ) is maintained for Monochromatized $\mathrm{Cu}$ KR1. The collection of diffraction is done only when the pattern is maintained from $45 \mathrm{kV}-40 \mathrm{~mA}$. The step scan rate maintains its level up to $3.00 \mathrm{~min}^{-1}$. And the time taken for the process is given as $0.400 \mathrm{sec}$.

\subsection{Chromium Ion Analysis}

After the adjustments of total electronic strength, the measurement of chromium ion concentration is done. The value of $\mathrm{pH}$ is measured by using the Orion 3-star ion meter. The relationship of chromium ion removal is calculated as shown in below:

Percentage removal $(\% \mathrm{R})=\mathrm{C}_{\mathrm{i}}-\mathrm{C}_{\mathrm{e}} / \mathrm{C}_{\mathrm{i}} \times 100$

Amount adsorbed $\left(\mathrm{q}_{\mathrm{e}}\right)=\left(\mathrm{Ci}-\mathrm{C}_{\mathrm{e}} / \mathrm{m}\right) \mathrm{V}$

$\mathrm{V}=$ Vol.of $\mathrm{Cr}$ test solution in liters

The initial and final concentration of chromium (VI) is given as $C_{i}$ and $C_{e}$. The mass of the carbons available in chromium is given as $\mathrm{m}$. the duplicate runs are analyzed based on the average values. To remove the error in data percentage is available between $\pm 1-2 \%$ and the amount of data is absorbed is $+0.005-0.01 \mathrm{mg} / \mathrm{g}$.

\section{ANALYSIS OF RESULTS}

From table 1 and 2, the different types of properties of NVAC, active carbons are shown. The surface area for $\mathrm{NVAC}$ of BET surface is given as $458 \mathrm{~m}^{2} / \mathrm{g}$. from literature, it can be studied that it is more than the active carbons. The literature is given as Cornelian cherry $\left(449 \mathrm{~m}^{2} / \mathrm{g}\right)$ Apricot shells $\left(412 \mathrm{~m}^{2} / \mathrm{g}\right)$ and stone $\left(369 \mathrm{~m}^{2} / \mathrm{g}\right)$.

From the process of adsorption, effectiveness is obtained in the features. The chromium (VI) will be on the surface of NVAC because there will be reduction the surface area from $458 \mathrm{~m}^{2} / \mathrm{g}$ to $390 \mathrm{~m}^{2} / \mathrm{g}$. rin the same way the size of pore is reduced from 15.126 to $14.974^{0} \mathrm{~A}$.in the surface of $1000 \mathrm{x}$, the carbons are activated based on the magnification process and the micrographs of SEM is examined. From figure 2, the microspores are shown and identified. By using the Boehm's method, the specific acidic group is measured. Hence all these are compared with the results of activated carbons from bio adsorbents.

\subsection{EDX Data}

The EDX data is shown from figure (2) and tabular form (2). Before and after the adsorption process, samples of spectrum are compared. Hence small peak spectrum is noted from the chromium. This data is analyzed and shown in table 2. Here the concentration level of oxygen is decreased based on the process of adsorption. In the same way, the concentration of chromium (VI) also increased. Now, the ion of chromium is replaced with the ion of oxygen atom. 


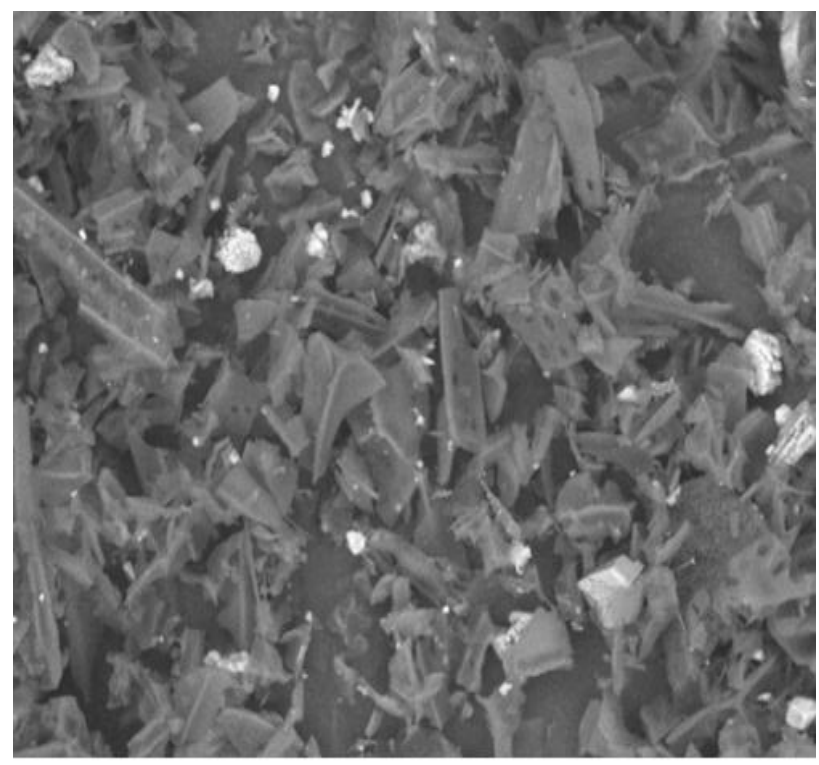

Fig. 2: SEM analysis of NVAC (before) at X50 magnifications

Report Date: 15:07:2014, 11:43:27

EDX SPECTRA

Sampele Nanive: NVaC 1

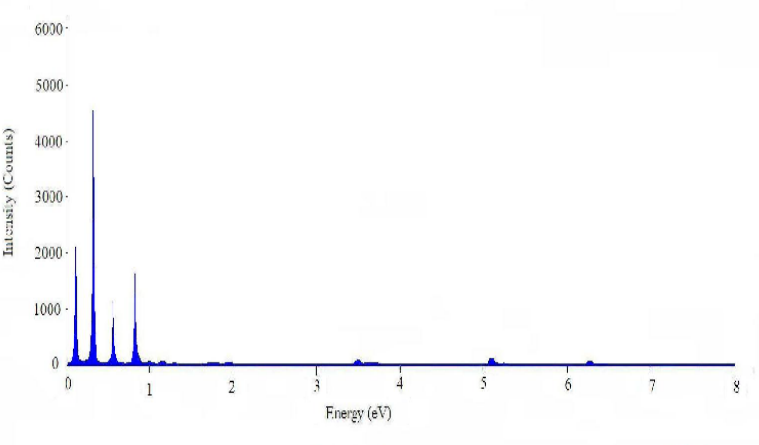

Fig. 3: Before Analysis Of Energy Dispersive X-Ray (EDX)

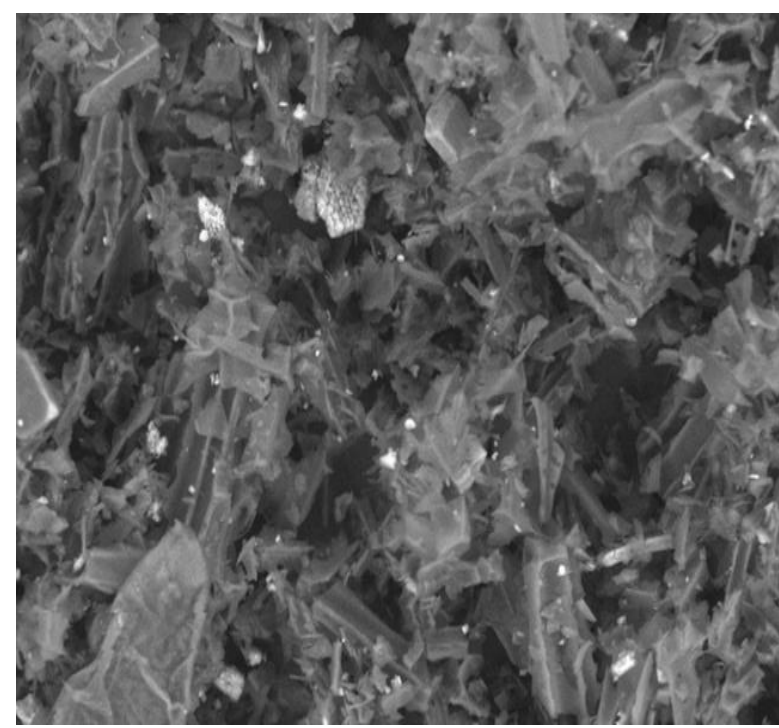

Fig. 4: SEM analysis of NVAC (After) at X50 magnifications

Repurl Dalk: 15:07/2014, 12:36:01

EDX SPECTRA Sarupele Narne: NVAC 2

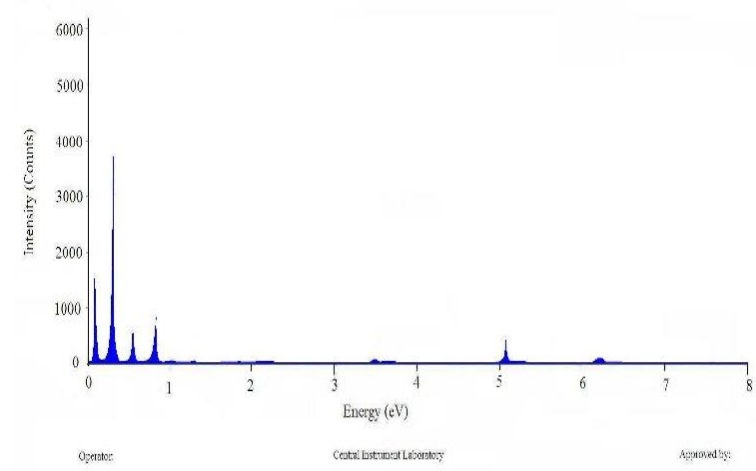

Fig. 5: After Analysis Of Energy Dispersive X-Ray

Based on the range of $\mathrm{PH}$ (2-7), the groups of carboxyl are dissociated. Near to the $\mathrm{pH}$ range, the chromium value is increased in the NVAC. From this it can be observed that the adsorbent level gives effective treatment for chromium ion containing water. Because of the oxidation of sulphuric acid, small amount of sulphur is added to the adsorbent. Therefore, the comparison of concentrations for nitrogen, hydrogen and oxygen is shown.

There will be change in the adsorption reactions from crystalline and molecular structure. Here valuable information is provided after the process of adsorption reaction. From fig 6 , the patterns of XRD for NVAC are given before and after the process of adsorption. Without altering the structure of adsorbent, the NVAC is loaded into the chromium (VI). This will exhibit the variations of crystal in the structure. The chromium will be physical in nature by using batch absorption experiments, the observations are collaborated.

\section{$3.2 X R D$}

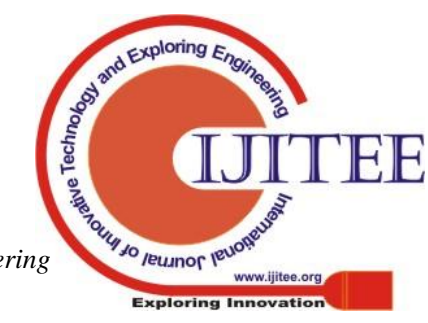




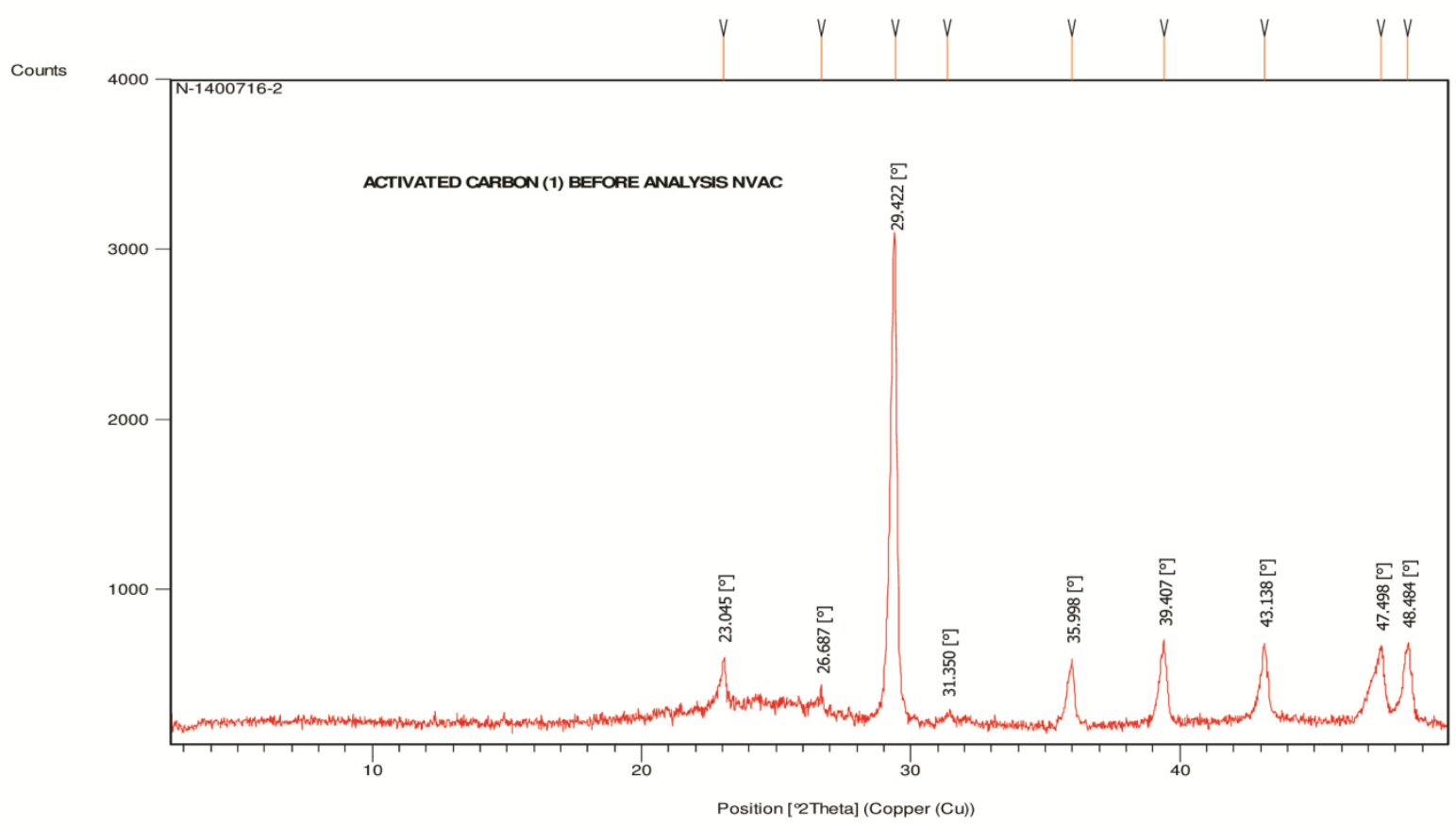

Fig. 6: Before Analysis Of XRD

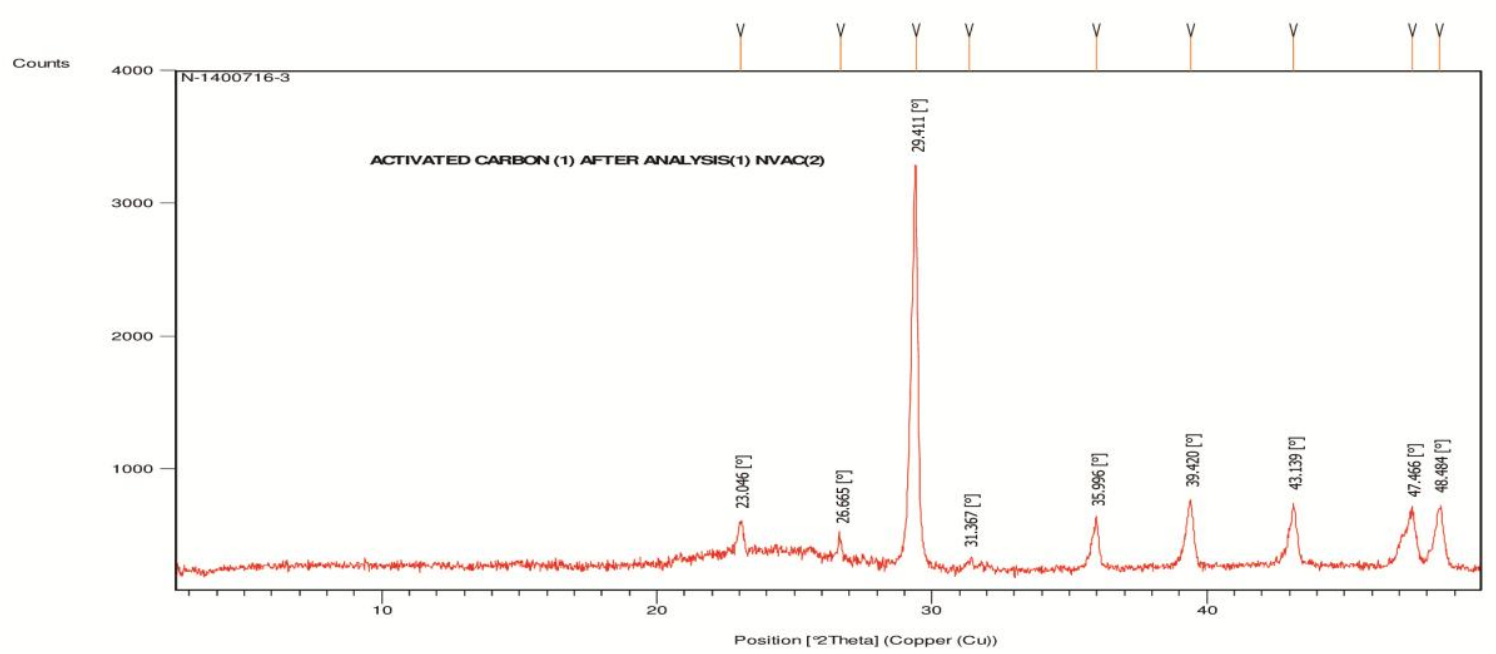

Fig. 7: After Analysis Of XRD

Basically, on the surface of carbon materials, Fourier transform infrared (FT-IR) spectroscopy is used. From figure 4 , the bands which are assigned to the NVAC are observed and they are group of specific functions available in the literature. The sharp and intense band groups are obtained at $3736 \mathrm{~cm}^{-1}$. This will vibrate and stretch of $\mathrm{OH}^{-}$ using the acids, alcohols and phenols. The range $3200-$ $3600 \mathrm{~cm}^{-1}$ is maintained for broad band and intense band which is centered at the $3393 \mathrm{~cm}^{-1}$. By using amines and amides, the stretching and vibration of $\mathrm{N}-\mathrm{H}$ is done. The mythylene group is used to stretch the $\mathrm{C}-\mathrm{H}$ at $2922 \mathrm{~cm}^{-1}$. In the same way the Amine group will stretch and vibrate the peak up to $2361 \mathrm{~cm}^{-1}$ [20 ir-11]. Because of aromatic and aliphatic stretching and vibrations, wide band range is set up to $1650-1600 \mathrm{~cm}^{-1}$.

The $-\mathrm{SO}_{3} \mathrm{H}$ group represents the exchange of ions mechanism and the band is maintained up to $1161 \mathbf{c m}^{-1}$. $1118 \mathrm{~cm}^{-1}$. The $\mathrm{C}-\mathrm{O}$ will stretch and vibrate up to the range of $1000-1068 \mathrm{~cm}^{-1}$ by using the alcohols, ethers, phenols and esters. The stretching and vibration of the group $\mathrm{S}=\mathrm{O}$, the peak value is maintained at the $831 \mathrm{~cm}^{-1}$. The C-S [ir-5] stretching and vibration is maintained their peak value up to $662 \mathrm{~cm}^{-1}$. In the adsorption process the $\mathrm{C}-\mathrm{Cr}$ peak value is absent. 


\section{$3.3 F T-I R$}

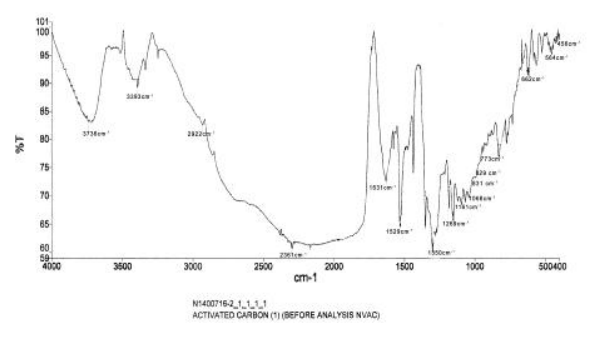

Fig. 8: Before Analysis Of FT-IR

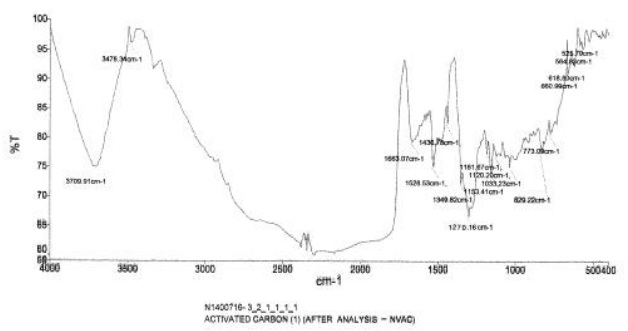

Fig. 9: After Analysis Of FT-IR

\subsection{Effect Of $p H$}

Basically, the solution of $\mathrm{pH}$ is mainly affected by the process of adsorption. The $\mathrm{pH}$ content is maintained from 210 in the adsorption process. This process is done only by using the solutions of $\mathrm{HCl}$ and $\mathrm{NaOH}$ which are diluted.

In the acidic media, the adsorption process will be processed in a metal and gives maximum value. By maintaining the $\mathrm{pH}$ value 2, maximum value of adsorption is obtained in the chromium. By using the both $\mathrm{H}^{+}$and $\mathrm{OH}^{-}$ ions, $\mathrm{pH}$ value are varied from high to very low. The adsorption will be decreased when the charged ions of positive and negative will be competed. Hence by maintaining the $\mathrm{pH}$ value from high to low, the metal gives adsorption value very low. Good absorption value is maintained when the ions of perception is taken from the hydroxide.

In bio-adsorbents, the functional groups and phenomenon of adsorption is related with the value of $\mathrm{pH}$. By using the groups of amino acids, carbohydrates, carboxylic groups and hydroxide groups. At the various levels of $\mathrm{pH}$ value, the groups which are functioned will be associated. Hence in the adsorption process, surface chemistry plays an major role.

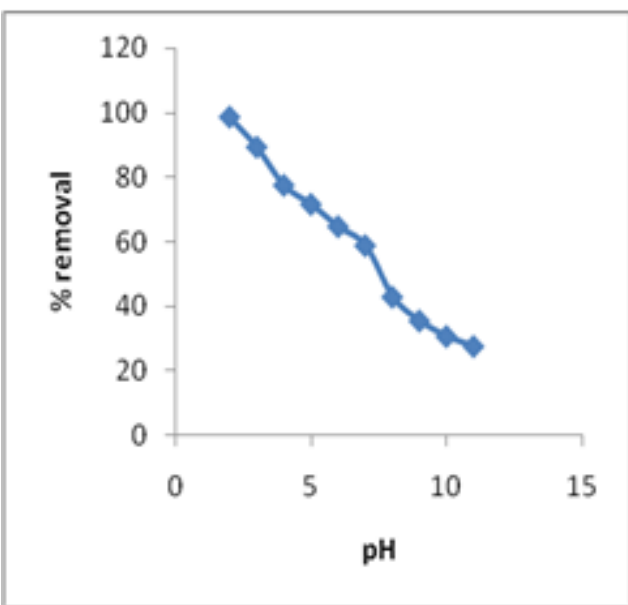

Fig. 10: plot of percentage removal of $\mathrm{Cr}(\mathrm{VI})$ as a function of $\mathrm{pH}$

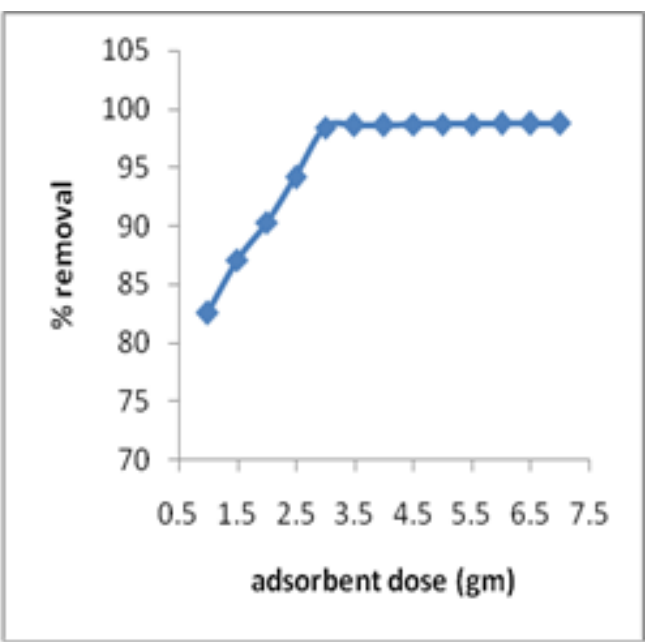

Fig.11: plot of percentage removal of $\mathrm{Cr}(\mathrm{VI})$ as a function of adsorbent dose

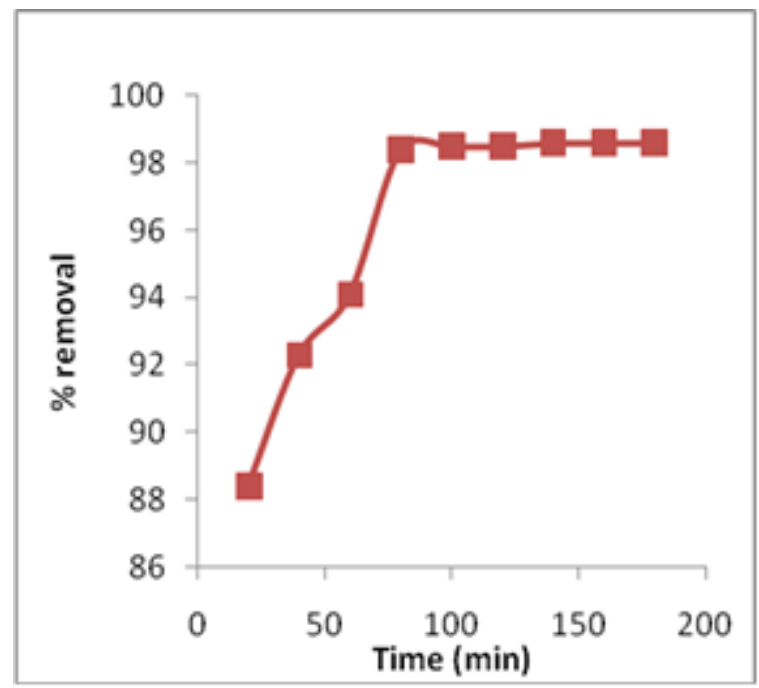

Fig. 12: plot of percentage removal of $\mathrm{Cr}(\mathrm{VI})$ as a function of contact time(min) 


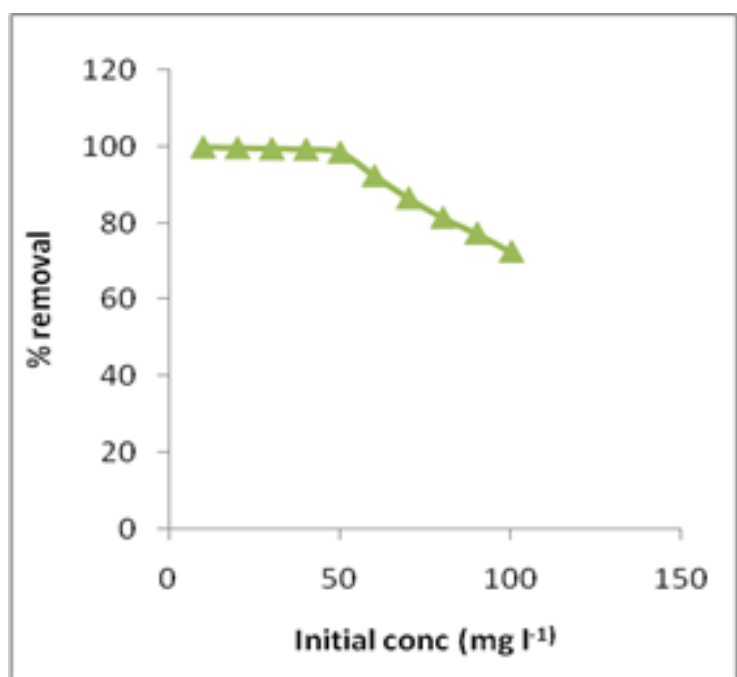

Fig. 13: plot of percentage removal of $\mathrm{Cr}(\mathrm{VI})$ as a function of ion solution

\subsection{Effect Of Adsorbent Concentration (Dose)}

By varying the dosage of adsorbent levels, the chromium percentage is removed. All this is mainly depends on the optimum condition and the value is maintained at $1.0 \mathrm{~g}$ $3.0 \mathrm{~g} / \mathrm{L}$. the chromium ion of initial concentration is maintained at $50 \mathrm{mg} / \mathrm{L}$. the time of contact of chromium is maintained at is $30^{\circ} \mathrm{C}$. There will be increase in the growth of adsorbent if the chromium percentage is removed. Here there will be increase of removal of percentage in the chromium ions if the number of sites increases.

\subsection{Effect Of Initial Adsorbate Concentration}

Here the amount of chromium ions is removed by using the adsorbent concentration in SAVAC. Here the dosage is fixed with $3.0 \mathrm{~g} / \mathrm{L}$ adsorbent of time 80 minutes at $30^{\circ} \mathrm{C}$ temperature. The concentration is varied from the chromium ions between 10.0 to $50.0 \mathrm{mg} / \mathrm{L}$.

The initial concentration value of the chromium ions are decreased with increased value. This variation is occurred due to the less number of active sites in the chromium ions. Here the concentration of chromium is increased from 10.0 to $100.0 \mathrm{mg} / \mathrm{L}$, and in the same way, the concentration of chromium is decreased from 100.0 to 72.50 . if the concentration of chromium ions are increased in then there will be increase In value exponentially 2.5 to $3.0 \mathrm{mg} / \mathrm{L}$ is changed from the fixed amount. This will increased from the 10 to $100 \mathrm{mg} / \mathrm{L}$.

\subsection{Adsorption Isotherms}

To represent the equilibrium states in the system of adsorption, adsorption isotherm is used. Adsorbate concentration is interfaced with the solid solutions. In the design process, mainly isotherm data is developed by using an equation. To describe the isotherms of adsorption, some adsorption equations are introduced. Here the temperature is maintained constant for the treatment of water applications.

The equation for Freundlich isotherm equation is given below

$\log \left(\mathrm{q}_{\mathrm{e}}\right)=\log \mathrm{K}_{\mathrm{f}}+(1 / \mathrm{n}) \log \mathrm{C}_{\mathrm{e}}$

The equation for linearization of Langmuir is given as $\mathrm{q}_{\mathrm{e}}=\mathrm{k}_{\mathrm{L}} \mathrm{C}_{\mathrm{e}} /\left(1+\mathrm{a}_{\mathrm{L}} \mathrm{C}_{\mathrm{e}}\right)$

The isotherm model for the dimensionless constant is given as below equation
$\mathrm{R}_{\mathrm{L}}=1 / 1+\mathrm{a}_{\mathrm{L}} \mathrm{C}_{\mathrm{i}}$

Here, the constants of Freundlich are represented by using the $\mathrm{K}_{\mathrm{f}}$ and $1 / \mathrm{n}$. The concentration of the chromium ion (VI) is represented by using $\mathrm{C}_{\mathrm{i}}$. The ions that are absorbed per unit weight of adsorbent is given by using the $\mathrm{q}_{\mathrm{e}}(\mathrm{mg} / \mathrm{g})$. The capacity and energy adsorption terms are represented by using the terms a and $b$.

Here the concentration is maintained at the linearity level, in the chromium ion (VI). This is equal to the model of isotherm by confirming the Freundlich applicability.

The separation factor, for the adsorption process in chromium ion is given as linear $\quad\left(\mathrm{R}_{\mathrm{L}}=1\right)$, irreversible $\left(\mathrm{R}_{\mathrm{L}}=0\right)$, unfavorable $\left(\mathrm{R}_{\mathrm{L}}>1\right)$, and favorable $\left(0<\mathrm{R}_{\mathrm{L}}<1\right)$. This is introduced by the hall. Hence the removal of adsorption is favorable to the chromium ions which are removed from the adsorbent.

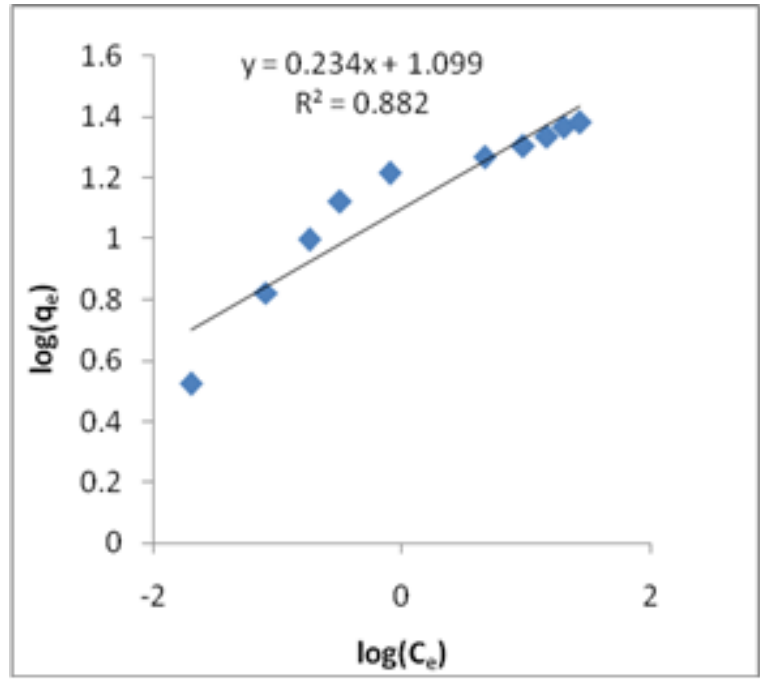

Fig. 14: Freundlich isotherm

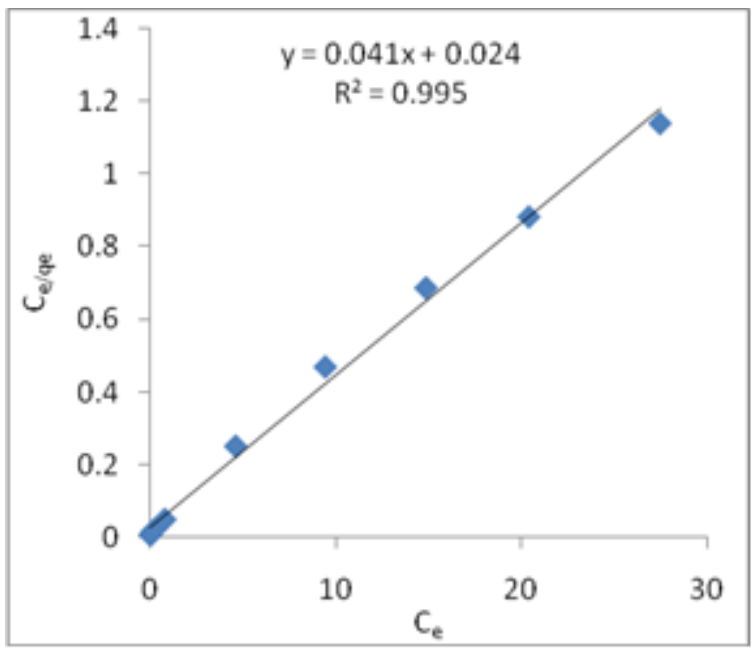

Fig. 15: Langmuir isotherm

\subsection{Effect Of Agitation Time}

In the adsorption kinematics, the calculation of agitation time plays an important role. Here the time is increased by maintaining the equilibrium condition for 80 minutes and because of this the removal of chromium ions are done.

Blue Eyes Intelligence Engineering

$\&$ Sciences Publication 


\subsection{Kinetic Study Of Adsorption Process}

The adsorption reaction will give about the description of kinetic in adsorption. The efficiency of adsorption is obtained by maintaining the characteristics. The behavior of active carbons in NVAC is maintained by using the kinetics of adsorption. The below table shows the representation of kinetics and adsorption parameters.

Table 4. Kinetics and adsorption parameters

\begin{tabular}{|l|l|l|l|}
\hline Adsorption Isotherm & slope & Intercept & $\mathbf{R}^{\mathbf{2}}$ \\
\hline Freundlich Isotherm & 0.234 & 1.099 & 0.882 \\
\hline Langmuir Isotherm & 0.041 & 0.024 & 0.995 \\
\hline $\begin{array}{l}\text { Pseudo first order } \\
\text { kinetics }\end{array}$ & -0.021 & 1.069 & 0.875 \\
\hline $\begin{array}{l}\text { Pseudo second order } \\
\text { kinetics }\end{array}$ & 0.058 & 0.374 & 0.998 \\
\hline $\begin{array}{l}\text { Weber and Morris } \\
\text { intra particle diffusion } \\
\text { model }\end{array}$ & 0.451 & 11.29 & 0.589 \\
\hline $\begin{array}{l}\text { Bangham's } \\
\text { diffusion model }\end{array}$ & 0.587 & -0.974 & 0.854 \\
\hline Elovich model & 2.090 & 6.389 & 0.730 \\
\hline
\end{tabular}

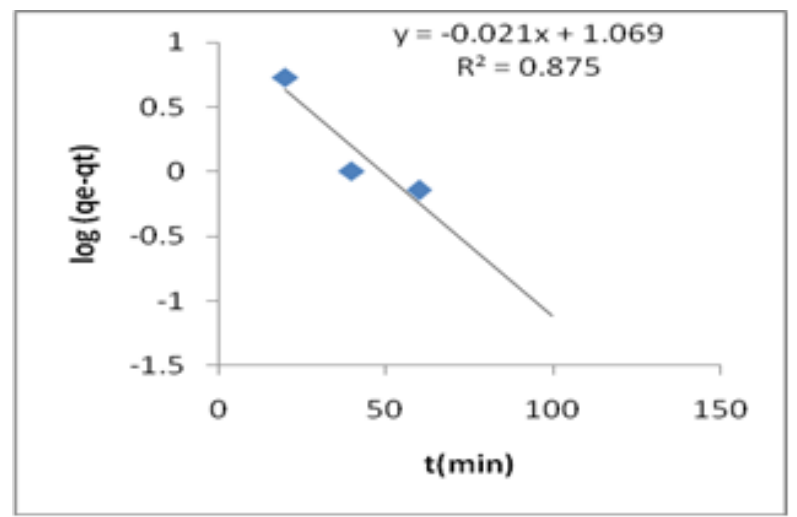

Fig. 16: Pseudo first order

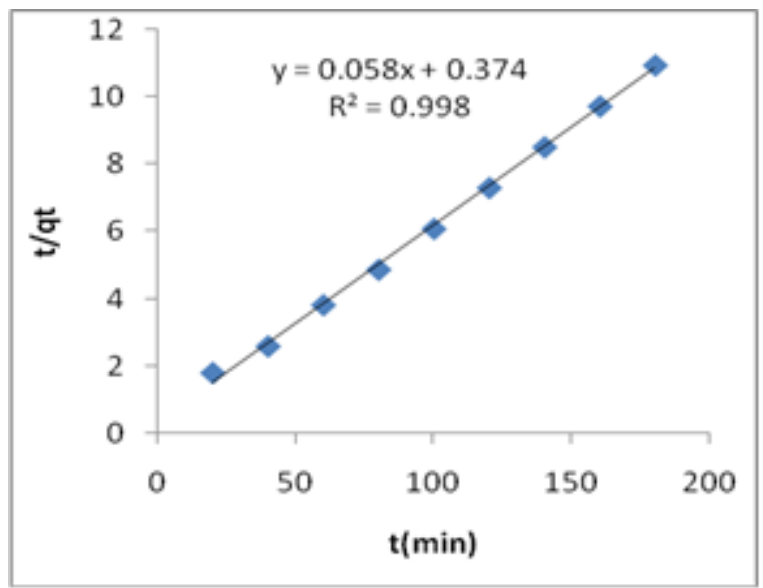

Fig. 17: Pseudo second order

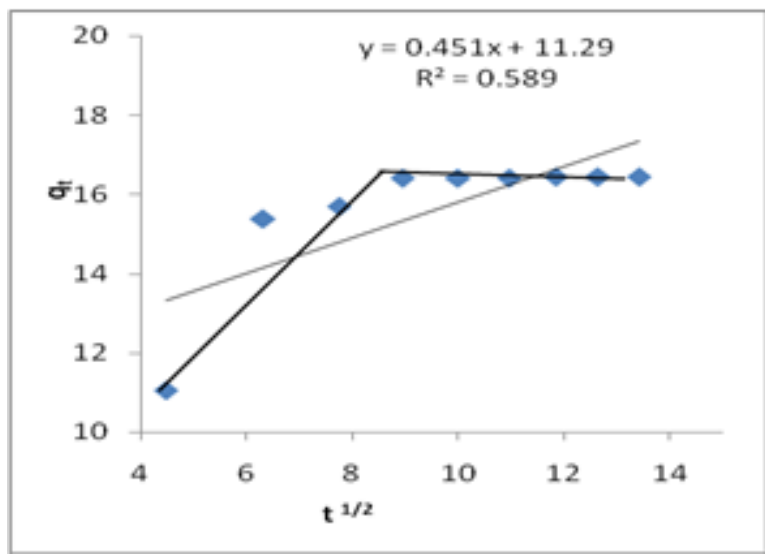

Fig. 18: Weber and Morris intra particle diffusion

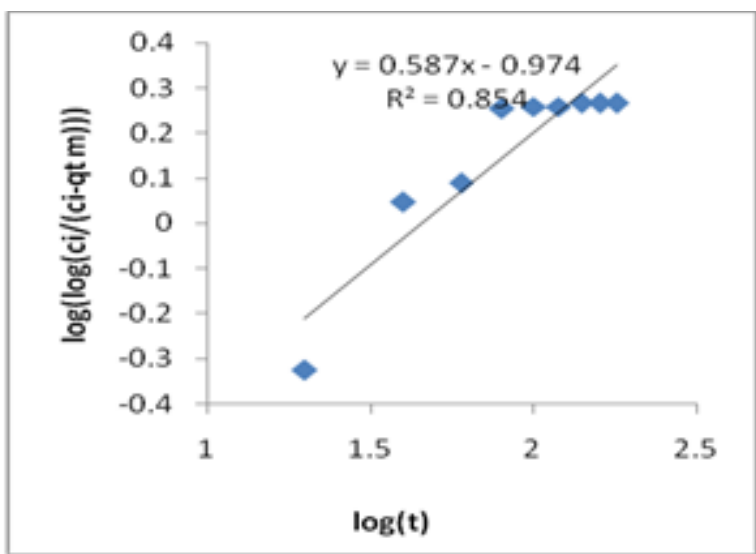

Fig. 19: Bangham's pore diffusion

\section{CONCLUSION}

In this paper the removal of chromium ions from the polluted water is presented. Here different types of properties of chemical of chromium (VI) are studied. Here adsorption temperature, $\mathrm{pH}$ value and chromium ion concentration also investigated using active carbons. From results, we can observe that the introduced system will reduce the percentage of chromium ions from the polluted water. Hence, the reduction in $\mathrm{pH}$ solution will be apparent in nature.

\section{REFERENCES}

1 Marja E, Gonzalez R, Williams CJ, Gardiner PHE. Environmental Science \& Technology, 2001, 35, 30253030.

2 Cossich ES, Tavares CRG, Ravagnani TMK. E. Journal of Biotechnology, 2002, 5(2), 133-140.

3 Z. Yue, S.E. Bender, J. Wang, J. Economy, J. Hazard. Mater, 2009, 166, 74.

4 Barrera H, Nunex FU, Bilyeu B, Diaz CB. Journal of Hazardous Materials, 2006, 136, 846-853.

5 J. Qiu, Z. Wang, H. Li, L. Xua, J. Peng, M. Zhai, C. Yang, J. Li, G. Wei, C. Yang, J. Li, G. Wei, J. Hazard. Mater. 166, 270, (2009)

6 J. Lakatos, S.D. Brown, C. E. Snape, Fuel 81, 691, (2002).

7 S.A. Cavaco, S. Fernandes, M.M. Quina, L.M. Ferreira, J. Hazard. Mater. 144, 634, (2007). 
8 N. Kongsricharoern, C. Polpraset, Water Sci. Technol. 34, 109, (1996).

9 G.Pugazhenthi, S. Sachan, N. Kishore, A. Kumar, J. Membr. Sci. 254, 229, (2005).

10 D. Lu, Q. Cao, X. Cao, F. Luo, J. Hazard. Mater. 166, 239, (2009).

11 W. Omar, H. Al- Itawl, Am. J. Appl. Sci. 4, 502, (2007).

12 M. Nadeem, A. Mahmood, SA. Shaid, AM. Khalid, G. Mckay. J. Hazard. Mater.B138, 604-613, (2007).

13 G.S. Agarwal, H. K. Bhuptawat, S. Chaudhari, Biosorption of watery Chromium (VI) by Tamarindus indica seeds, Bioresour. Technol. 97, 949-956(2006).

14 V.Sarin, K.K. Pant, Removal of chromium(VI) from industrial waste by using eucalyptus bark, Bioresour. Technol. 97 (1) 15- 20 (2006)

15 E. Malkoc, Y. Nuhoglu, The evacuation of chromium(VI) from manufactured wastewater by Ulothrix zonata, Fresen. Environ. Bull. 12(4) 376-381 (2003).

16 K. Vijayaraghavan, J. Jegan, K. Palanivelu, M. Velam, Biosorption of cobalt (II) and nickel (II) via ocean growth: cluster and section thinks about, Separ. Purif. Technol. 44, 53-59 (2005).

17 K. Kadirvelu, K.Thamaraiselvi, C. Namasivayam, Adsorption of Nickel (II) from aqueous solution onto activated carbon prepared from coirpitch, Separ. Purif. Technol. 24, 497-505 (2001).

18 S. Ricordel, S. Taha, I. Cisse, G. Dorange, Heavy metals removal by adsorption onto peanut husks carbob: Characterization, kinetic study and modeling, Separ. Purif. Technol. 24, 389-401 (2001).

19 A. A. Al-Haj, R. El-Bishtawi, Removal of lead and nickel particles utilizing Zeolite tuff, J. Chem. Tech. Biotechnol. 69, 27-34(1999).

20 D.Mohan, K.P. Singh, V.K. Singh, Removal of hexavalent chromium from watery arrangement utilizing minimal effort actuated carbons got from farming waste materials and enacted carbon texture fabric, Indust. Eng. Chem. Res. (ACS) 44, 1027-1042(2005). 